\title{
Model Prediksi Kadar Air Buah Cabai Rawit Domba (Capsicum frutescens L.) Menggunakan Spektroskopi Ultraviolet Visible Near Infrared
}

\section{Prediction Model of Water Content of Domba Cayenne Pepper Fruit (Capsicum frutescens L.) Using Ultraviolet Visible Near Infrared Spectroscopy}

\author{
Kusumiyati $^{10}$, Ine Elisa Putri ${ }^{2}$ dan Agus Arip Munawar ${ }^{3}$ \\ ${ }^{1}$ Departemen Budidaya, Fakultas Pertanian, Universitas Padjadjaran, Jatinangor \\ ${ }^{2}$ Program Studi Magister Agronomi, Fakultas Pertanian, Universitas Padjadjaran, Jatinangor \\ ${ }^{3}$ Jurusan Teknik Pertanian, Fakultas Pertanian, Universitas Syiah Kuala, Aceh \\ `Email korespondensi: kusumiyati@unpad.ac.id
}

\begin{abstract}
This research was aimed to estimate the water content of domba cayenne pepper fruit (Capsicum frutescens L.) using ultraviolet visible near infrared (UV-Vis-NIR) spectroscopy. The total samples used were 45 fruits. The analysis was carried out at the Horticulture Laboratory, Faculty of Agriculture, Universitas Padjadjaran. Spectral data acquisition with a wavelength range of $300-1050 \mathrm{~nm}$ (Nirvana AG410). The spectra were corrected by using multiplicative scatter correction (MSC), standard normal variate transformation (SNV), orthogonal signal correction $(\mathrm{OSC})$, first derivative (dg1) and second derivative (dg2) methods. Data analysis was perfomed using partial least squares regression (PLSR). Based on this research, the results showed that the OSC correction method produced the highest calibration model with $R_{c a}, R M S E C, R_{v a l}, R M S E C V, R P D$ and the factor were 0.99, 0.31, 0.98, 0.68, 6.62 and 4, respectively. This indicated that UV-Vis-NIR spectroscopy can be used to predict the water content of domba cayenne papper fruit.
\end{abstract}

Keywords: calibration model, correction method, intact fruit, non-destructive, prediction

\begin{abstract}
Abstrak. Penelitian ini bertujuan untuk menduga kadar air buah cabai rawit domba (Capsicum frutescens L.) menggunakan spektroskopi UV-Vis-NIR. Total sampel yang digunakan yaitu 45 buah. Analisis dilakukan di Laboratorium Hortikultura, Fakultas Pertanian, Universitas Padjadjaran. Akuisisi data spektra dengan rentang panjang gelombang 300 - $1050 \mathrm{~nm}$ (Nirvana AG410). Spektra diperbaiki dengan metode multiplicative scatter correction (MSC), standard normal variate transformation (SNV), orthogonal signal correction (OSC), first derivative (dg1) dan second derivative (dg2). Analisis data dilakukan dengan menggunakan partial least squares regression (PLSR). Berdasarkan penelitian ini menunjukkan bahwa metode koreksi OSC menghasilkan model kalibrasi tertinggi dengan $\mathrm{R}_{\mathrm{kal}}$, RMSEC, $\mathrm{R}_{\mathrm{val}}$, RMSECV, RPD dan faktornya masing-masing yaitu 0.99, 0.31, 0.98, 0.68, 6.62 dan 4. Hal ini menunjukkan bahwa spektroskopi UV-Vis-NIR dapat digunakan untuk memprediksi kadar air pada buah cabai rawit domba.
\end{abstract}

Kata kunci: buah utuh, metode koreksi, model kalibrasi, non-destruktif, prediksi

\section{PENDAHULUAN}

Buah cabai rawit merupakan salah satu golongan produk hortikultura. Buah ini dapat dikonsumsi dalam keadaan segar. Namun, buah yang dikonsumsi dalam keadaan segar memiliki kelemahan yaitu lebih cepat busuk. Sehingga diperlukan waktu panen dan penanganan pasca panen yang tepat agar daya simpan buah cabai rawit dapat lebih lama. Kesegaran dan daya simpan berhubungan dengan kandungan air buah. Kadar air buah cabai rawit cukup tinggi. Pada buah cabai rawit segar memiliki kandungan air hingga $\pm 83 \%$, sehingga petani tidak mau mengambil resiko dengan melakukan penyimpanan hasil panen buah cabai terlalu lama karena mudah rusak (Anoraga et al., 2018; Ramdani et al., 2019).

Buah cabai rawit yang semakin lama dipanen akan mengalami penurunan kandungan air. Hal ini salah satunya disebabkan oleh tranpirasi. Buah akan semakin keriput dan kusam. Penampilan buah akan semakin tidak segar/busuk apabila setelah dipanen dilakukan penyimpanan yang telalu lama. Buah cabai rawit yang dipanen merah memiliki kandungan air yang lebih sedikit daripada buah cabai rawit hijau. Berdasarkan pertimbangan tersebut, maka akan lebih mudah apabila buah yang telah dipanen diketahui terlebih dahulu kandungan air buah cabai rawit. Terutama bagi para pelaku industri, kadar air komoditas di bidang 
pertanian sangat penting dalam upaya memperkirakan waktu transportasi agar komoditas pertanian dapat tetap segar saat diterima di tangan konsumen. Namun, pengujian yang selama ini dikenal untuk mengetahui kadar air masih dengan menggunakan teknologi destruksi.

Pengujian dengan teknologi destruksi menyebabkan buah menjadi rusak dan memakan waktu yang lama. Namun, ada teknologi alternatif lainnya yaitu pengujian secara non-destruksi yang dapat digunakan untuk mengukur kadar air buah secara cepat, akurat dan tidak mengakibatkan buah menjadi rusak/memar. Teknologi ini dianggap sebagai solusi untuk mendapatkan pendugaan nilai kadar air dengan cepat, akurat dan ramah lingkungan. Salah satu teknologi non-destruksi yaitu menggunakan spektroskopi ultraviolet visible near infrared (UV-Vis-NIR).

Spektroskopi UV-Vis-NIR telah banyak digunakan untuk menguji kualitas buah. Salah satu parameter pengujian kualitas buah yang dideteksi yaitu kadar air buah-buahan. Penerapannya telah diuji dapat mendeteksi nilai kadar air pada buah sawo (Kusumiyati. et al., 2018), alpukat (Blakey \& Rooyen, 2011) dan kurma (Mireei et al., 2010). Hal ini membuktikan bahwa spektroskopi memiliki potensi untuk digunakan menduga nilai kadar air sehingga pelaku industri dapat memperkirakan estimasi waktu lamanya distribusi dan lamanya waktu ketahanan simpan produk pertanian. Spektrum spektroskopi yang terambil dapat memiliki noise yang dapat menurunkan nilai keakuratan model. Indikator keakuratan suatu model yaitu koefisien korelasi (R), faktor, root mean squares error of calibration/validation (RMSEC/RMSECV), dan ratio performance to deviation (RPD).

Noise dapat direduksi menggunakan berbagai metode koreksi spektra. Penggunaan metode koreksi spektra dapat menjadikan model kalibrasi lebih akurat karena noise yang terdapat pada spektrum dapat diperbaiki atau direduksi (Rinnan et al., 2009). Beberapa pra pengolahan data yang dapat digunakan yaitu multiplicative scatter correction (MSC), standard normal variate transformation
(SNV), orthogonal signal correction (OSC), first derivative $(\mathrm{dg} 1)$ dan second derivative (dg2). MSC bekerja dengan cara melakukan koreksi berdasarkan rata-rata set data spektrum hingga didapatkan kecocokan semirip mungkin dengan spektrum rujukannya (Ramadhan et al., 2016). SNV merupakan koreksi pada spektrum yang memusatkan pada rata-rata masingmasing spektra secara individual dan dapat mengurangi efek dari hamburan yang berasal dari bahan yang berpengaruh pada spektra (Kurniasari et al., 2017). Pra pengolahan data OSC adalah menghilangkan keragaman nilai $\mathrm{X}$ (spektra) yang tidak berhubungan dengan data Y (data destruksi/analisis laboratorium). Dg1 dan dg2 dipergunakan untuk memperjelas puncak dan lembah pada spektrum original yang tumpang tindih.

Metode koreksi spektra telah diaplikasikan pada berbagai komoditas pertanian. Iqbal et al., (2014) melaporkan bahwa dg1 menghasilkan model kalibrasi karoten terbaik dengan $\mathrm{R}^{2} 0.84$ dan RMSEC yaitu 0.03 sedangkan SNV merupakan metode koreksi spektra terbaik untuk kadar air dengan $\mathrm{R}^{2} 0.89$ serta RMSEC 5.72 pada tandan buah segar (TBS) kelapa sawit, kadar air bawang bombay dengan dg2 mendapatkan hasil model kalibrasi terbaik dengan $\mathrm{R}^{2} 0.96$ serta RMSEC 1.30 (Jantra et al., 2017), dan pada asam tertitrasi buah mangga memperoleh nilai $\mathrm{R}^{2}$ tertinggi yaitu 0.98 serta RMSEC 15.11 dengan menggunakan dg1+SNV (Munawar et al., 2016).

Metode koreksi OSC menunjukkan model kalibrasi tertinggi pada buah tomat dan jambu biji, Saad et al., (2014) melaporkan bahwa dengan OSC parameter likopen, total padatan terlarut (TPT) dan kadar asam buah tomat mendapatkan $\mathrm{R}^{2}$ tertinggi masing-masing 0.99, 0.99 dan 0.98 serta (Kusumiyati et al., 2020) menyebutkan bahwa TPT jambu biji yang dikoreksi dengan OSC menghasilkan nilai kalibrasi $\mathrm{R}^{2}$ terbaik yaitu 0.85 . Namun pengujian penggunaan spektroskopi UV-VisNIR untuk menduga nilai kadar air pada buah cabai rawit belum banyak dilakukan oleh para peneliti, Berdasarkan uraian tersebut di atas maka tujuan dari penelitian ini adalah untuk mengkaji penggunaan spektroskopi UV-Vis- 
NIR untuk menduga nilai kadar air buah cabai rawit domba serta memperoleh metode koreksi spektra terbaik untuk mendapatkan model kalibrasi.

\section{METODE}

Sampel yang digunakan pada penelitian ini yaitu buah cabai rawit domba yang dikelompokkan ke dalam tiga tingkat kematangan. Buah cabai rawit domba hijau, oranye dan merah. Masing-masing kematangan terdiri atas 15 unit sampel, sehingga total terdapat 45 unit sampel. Tiap 1 unit sampel merupakan kumpulan dari buah cabai rawit \pm 30 gr. Total sampel yang dibutuhkan yaitu \pm 1.35 $\mathrm{kg}$. Bahan yang digunakan untuk membantu proses pengeringan sampel yaitu aluminium foil. Alat yang digunakan yaitu spektrometer UV-Vis-NIR (NirVana AG410, Integrated Spectronics Pty, Ltd, Australia) panjang gelombang 300-1050 $\mathrm{nm}$ interval $3 \mathrm{~nm}$ dipergunakan untuk meradiasi sampel dan diambil data spektrumnya, petridish berdiameter $10 \mathrm{~cm}$ (Anumbra) sebagai wadah sampel cabai rawit saat diradiasi dengan spektroskopi UV-Vis-NIR, oven (memmert schutzart din 40050-IP 20, Gemany) digunakan untuk mengeringkan sampel, timbangan digital (ACIS Digital Balance Model BC-500, Japan) dan timbangan analitik (Mettler Toledo AG245) untuk menimbang bobot, pisau dan talenan sebagai alas serta alat memotong sampel.

Penelitian dilaksanakan pada Bulan Mei hingga Agustus 2020. Penanaman dilakukan di Kebun Percobaan Hidroponik Fakultas Pertanian, Universitas Padjadjaran dan analisis kadar air dilakukan di Laboratorium Holtikultura, Fakultas Pertanian, Universitas Padjadjaran. Penelitian dilakukan dalam beberapa tahap yaitu pengukuran spektrum buah cabai rawit domba lalu pengujian kadar air kemudian analisis data yang diterapkan yaitu koreksi spektra terlebih dahulu sebelum didapatkan model kalibrasi. Keakuratan model kalibrasi diuji dengan cross validation. Sampel dimasukkan ke dalam 20 segment yang terdiri atas 2 - 3 sampel secara acak. Model kalibrasi dianalisis dengan menggunakan metode partial least square regression (PLSR) dan algoritma non-linear iteration partial least squares (NIPALS). Data diolah dengan menggunakan software unscrambler 10.4.

\section{Persiapan sampel}

Sampel buah cabai rawit dipanen dalam tiga tingkat kematangan, buah cabai rawit hijau 20 hari setelah bunga mekar (HSBM), oranye 40 HSBM dan merah 60 HSBM. Sampel yang telah dipanen dibawa ke Laboratorium Holtikultura dan dikelompokkan sesuai tingkat kematangan. Buah cabai rawit kemudian dipisahkan dari tangkainya lalu ditimbang \pm 30 gr per sampel, setelah ditimbang kemudian dimasukkan ke dalam petridish yang telah diberi alas oleh karton warna hitam. Sampel selanjutnya siap untuk dilakukan pengukuran dengan spektrometer UV-Vis-NIR.

\section{Pengukuran spektrum buah cabai rawit domba}

Buah cabai rawit yang telah berada di petridish kemudian diradiasi sebanyak 5 kali. Bagian yang diradiasi meliputi atas, bawah, kanan, kiri dan tengah petridish. Langkah tersebut kemudian diulangi hingga seluruh sampel diradiasi. Data spektrum per sampel kemudian dirata-ratakan. Spektrometer kemudian dihubungkan dengan USB untuk memindahkan data spektrum absorban ke laptop. Data selanjutnya diterjemahkan dengan bantuan software Integrated Software for Imagers and Spectrometers (ISIS) dan dibuka di aplikasi excel.

\section{Prosedur pengujian kadar air}

Kadar air diuji dengan metode gravimetri. Sampel dipotong kecil-kecil dan ditimbang $\pm 1 \mathrm{~g}$, lalu dimasukkan ke dalam aluminium foil. Sampel kemudian dirapikan di atas loyang dan dimasukkan ke dalam oven dengan suhu $105^{\circ} \mathrm{C}$. Sampel selanjutnya di keluarkan dan ditimbang setiap 3 jam sekali hingga didapatkan berat kering yang konstan. Perhitungan kadar air yaitu: 
$\%$ Kadar air $=\frac{\text { Berat basah }- \text { berat kering }}{\text { berat basah }} \times 100 \%$

\section{Aplikasi metode koreksi spektra}

Model kalibrasi yang berasal dari spektrum original (absorban) yang didapatkan kemudian diterapkan berbagai metode koreksi spektra. Data spektrum absorban yang telah didapatkan kemudian dikoreksi dengan multiplicative scatter correction (MSC), standard normal variate transformation (SNV), orthogonal signal correction (OSC), first derivative ( $\mathrm{dg} 1)$ dan second derivative (dg2).

\section{HASIL DAN PEMBAHASAN}

Data referensi buah cabai rawit domba dengan tiga tingkat kematangan

Tingkat kematangan pada buah cabai rawit tidak hanya menyebabkan perubahan warna kulit tetapi juga perubahan nilai kadar air. Pada tabel 1 nampak bahwa kadar air buah cabai rawit dengan tiga tingkat kematangan. Buah cabai rawit domba hijau memiliki kadar air sebesar $59.40 \%$ hingga $77.41 \%$, buah cabai rawit oranye kadar airnya yaitu $65.38 \%$ sampai $72.11 \%$ sedangkan buah cabai rawit merah kandungan airnya berkisar antara $61.15 \%$ hingga $71.91 \%$. Secara keseluruhan, dilihat dari nilai rata-rata kadar air buah cabai rawit berbagai tingkat kematangan mengalami penurunan. Kadar air buah cabai rawit hijau sebesar $73.28 \%$, buah cabai rawit oranye yaitu $69.38 \%$ dan buah cabai rawit merah $67.08 \%$. Hal ini menunjukkan bahwa buah cabai rawit yang semakin lama dipanen akan mengindikasikan berkurangnya air dalam buah. Hal ini sejalan dengan penelitian yang dilakukan oleh Khairiah et al., (2019) yang menyatakan bahwa kadar air buah cabai rawit domba yang semakin matang mengalami penurunan, yang disebabkan oleh transpirasi. Nilai standar deviasi menunjukkan besaran nilai keragaman dari sebuah sampel. Nilai standar deviasi untuk kadar air buah cabai rawit domba berbagai tingkat kematangan yaitu $4.50 \%$.

Tabel 1. Data referensi buah cabai rawit domba dengan tiga tingkat kematangan

\begin{tabular}{cccccc}
\hline Parameter & Tingkat kematangan & Minimum $(\%)$ & Maksimum $(\%)$ & Rata-rata(\%) & Standar Deviasi (\%) \\
\hline \multirow{3}{*}{ Kadar Air } & Hijau & 59.40 & 77.41 & 73.28 & \\
& Oranye & 65.38 & 72.11 & 69.38 & 4.50 \\
& Merah & 61.15 & 71.91 & 67.08 & \\
\hline
\end{tabular}

Spektrum absorban buah cabai rawit domba dengan tiga tingkat kematangan

Pola spektrum terbentuk dari interaksi antara cahaya dari berbagai panjang gelombang dan bahan organik dari sampel. Pada Gambar 1 nampak bahwa buah cabai rawit domba berbagai tingkat kematangan menghasilkan pola spektrum yang berbeda. Puncak dan lembah pada pola spektrum memiliki peran besar pada interpretasi data berbagai kandungan kimia sampel. Puncak dan lembah pada masing-masing tingkat kematangan yaitu buah cabai rawit hijau 510 $\mathrm{nm}, 639 \mathrm{~nm}$ dan $915 \mathrm{~nm}$, buah cabai rawit oranye yaitu $522 \mathrm{~nm}, 636 \mathrm{~nm}$ dan $915 \mathrm{~nm}$ sedangkan buah cabai rawit merah yaitu 528 $\mathrm{nm}$ dan $915 \mathrm{~nm}$. Cahaya yang diradiasikan pada sampel akan dipantulkan, diserap dan diteruskan sehingga ikatan atom $\mathrm{C}-\mathrm{H}, \mathrm{N}-\mathrm{H}$ dan $\mathrm{O}-\mathrm{H}$ akan mengalami vibrasi (Pasquini, 2003). Data bahan organik akan ditransformasikan ke dalam spektrum yang akan terbaca sebagai besaran kandungan kimia suatu produk. 


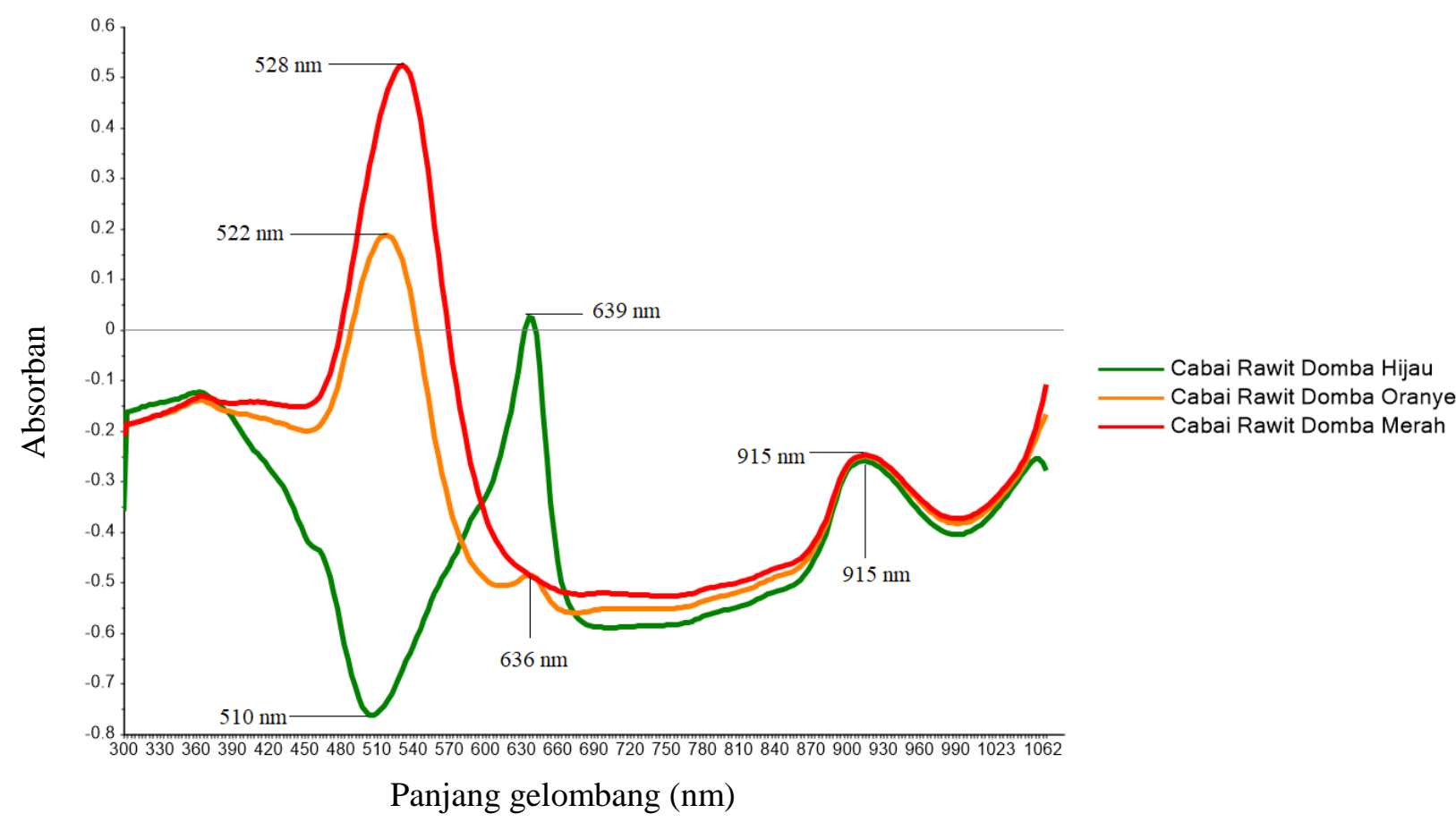

Gambar 1. Spektrum rata-rata absorban buah cabai rawit domba dengan tiga tingkat kematangan

Pada Gambar 2 merupakan spektrum absorban dan metode koreksi spektra OSC. Spektra yang telah dikoreksi dengan pra pengolahan data OSC menunjukkan perubahan dari spektra sebelumnya yaitu spektra original (absorban). Perubahan terjadi dengan cara mereduksi data spektra berdasarkan data analisis laboratorium.

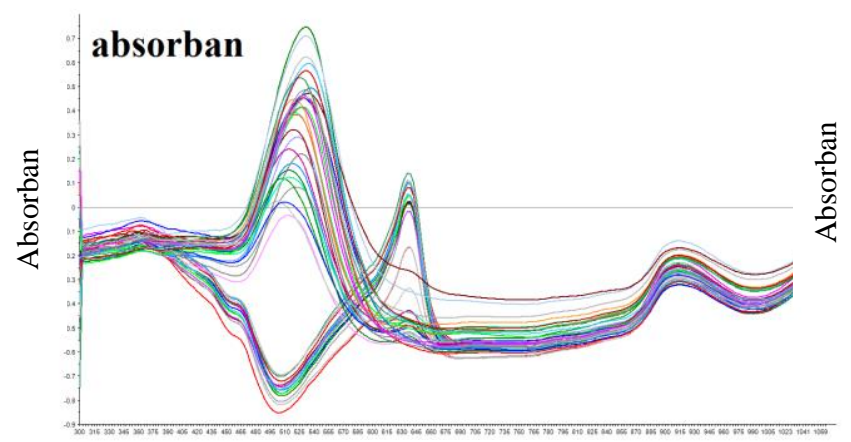

Panjang gelombang (nm)
Pada Gambar 3 terlihat sebaran perubahan dari data absorban menjadi data yan telah dikoreksi OSC. Data sebaran dari kalibrasi berwarna biru sedangkan validasi silang berwarna merah. Spektra yang telah diperbaiki dengan OSC terlihat sebaran data yang semakin mendekati garis regresi. Sebaran data yang semakin mendekati garis regresi menandakan model semakin akurat.

Gambar 2. Spektrum absorban dan pra-pengolahan data dengan OSC

Model kalibrasi dan validasi kadar air air buah cabai rawit domba

Kalibrasi dan validasi merupakan tahapan untuk mendapatkan suatu model untuk prediksi. Kalibrasi merupakan korelasi antara data spektra dan data destruksi/analisis laboratorium. Validasi ditujukan untuk menguji keakuratan dan ketepatan dari model kalibrasi yang dibangun. Pada Tabel 2 
diperoleh nilai kalibrasi dan validasi dari kadar air buah cabai rawit domba dengan spektra absorban (original) dan berbagai metode koreksi spektra. Model kalibrasi dengan spektra absorban mendapatkan nilai koefisien korelasi (R) terendah daripada metode koreksi spektra lainnya yaitu MSC, SNV, dg1, dg2 dan OSC.

Tabel 2. Nilai kalibrasi dan validasi kadar air buah cabai rawit domba

\begin{tabular}{|c|c|c|c|c|c|c|c|}
\hline \multirow[b]{2}{*}{ Parameter } & \multirow{2}{*}{ Spektra } & \multirow{2}{*}{ Faktor } & \multicolumn{3}{|c|}{ Kalibrasi } & \multirow{2}{*}{$\begin{array}{l}\text { Validasi } \\
\text { RMSECV }\end{array}$} & \multirow{2}{*}{ RPD } \\
\hline & & & $\mathrm{R}$ & RMSEC & $\mathrm{R}$ & & \\
\hline \multirow{6}{*}{ Kadar Air } & Absorban & 6 & 0.76 & 2.84 & 0.60 & 3.63 & 1.24 \\
\hline & MSC & 7 & 0.87 & 2.09 & 0.73 & 3.06 & 1.47 \\
\hline & SNV & 7 & 0.81 & 2.57 & 0.66 & 3.49 & 1.29 \\
\hline & dg1 & 5 & 0.83 & 2.44 & 0.69 & 3.17 & 1.42 \\
\hline & dg2 & 3 & 0.80 & 2.66 & 0.52 & 3.85 & 1.17 \\
\hline & OSC & 4 & 0.99 & 0.31 & 0.98 & 0.68 & 6.62 \\
\hline
\end{tabular}
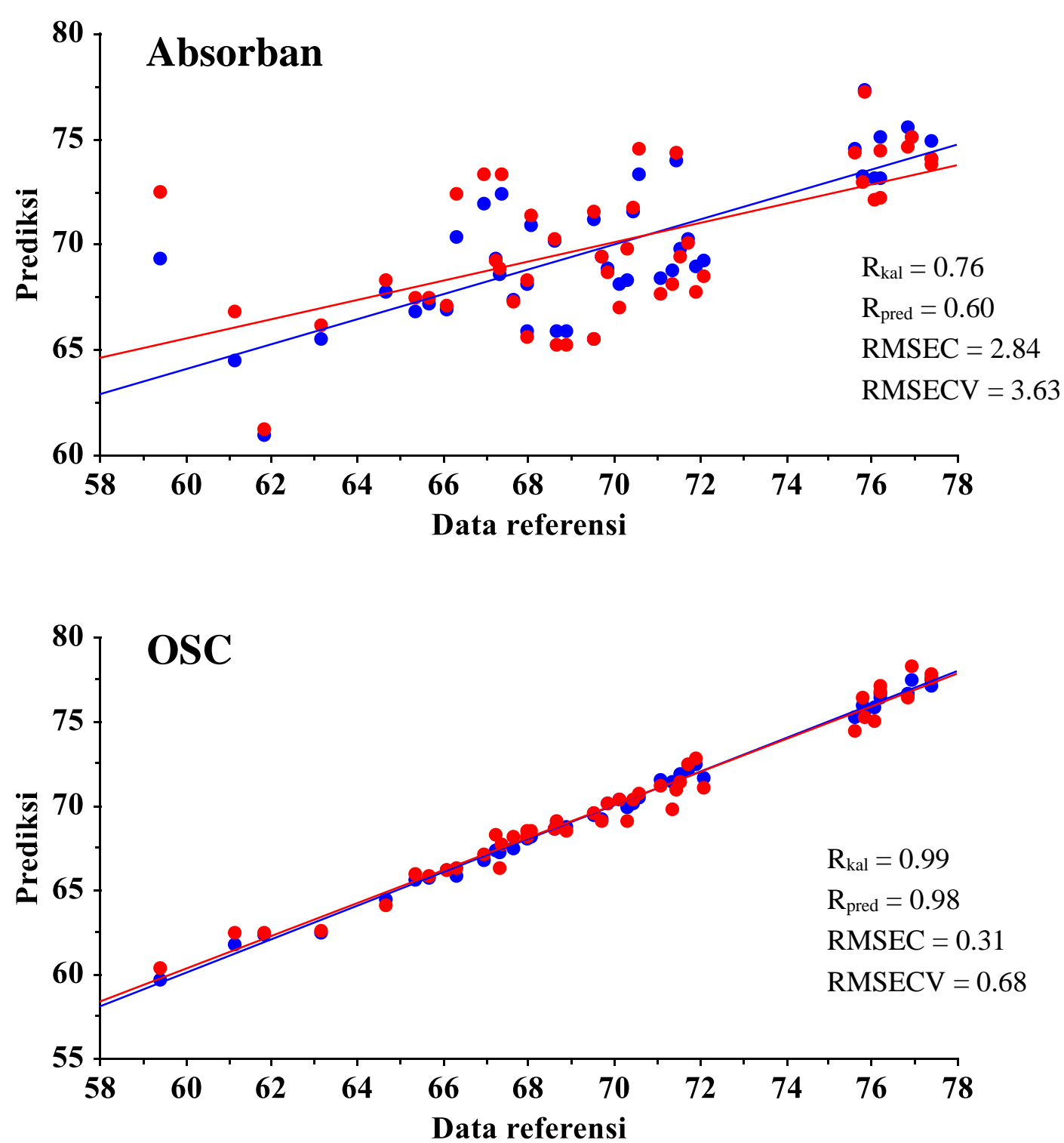

Gambar 3. Scatter plot spektrum original dan pra-pengolahan data dengan OSC 
Absorban mendapatkan $\mathrm{R} \quad 0.76$ sedangkan berbagai metode koreksi spektra menghasilkan model kalibrasi lebih akurat ketimbang absorban. Metode koreksi MSC, SNV, dg1, dg2 dan OSC masing-masing mendapatkan nilai $\mathrm{R}$ sebesar $\quad 0.87,0.81,0.83$, 0.80 dan 0.99. Berdasarkan hal tersebut, didapatkan bahwa OSC merupakan metode koreksi spektra terbaik untuk kadar air buah cabai rawit domba.

Spektra absorban yang telah dikoreksi oleh OSC memperoleh model kalibrasi tertinggi dengan nilai $\mathrm{R}$ yaitu 0.99 , RMSEC 0.31 , $\mathrm{R}$ validasi yaitu 0.98 , RMSECV 0.68 , faktornya 4 dan RPD 6.62. Nilai $R$ yang diperoleh diartikan bahwa pada model kalibrasi terdapat sebanyak 99\% dari data keseluruhan memiliki variabel terikat dapat dijelaskan oleh variabel bebasnya. Suatu model yang menghasilkan nilai $\mathrm{R}>0.71$ merupakan model efektif dan dapat digunakan untuk pendeteksian lebih lanjut (Williams, 2007). Rentang selisih nilai RMSEC dan RMSECV juga menjadi indikasi excellent model. Nicolaï et al., (2007) menyebutkan bahwa excellent model memiliki nilai $\mathrm{R}$ yang tinggi, RMSEC dan RMSECV yang rendah serta selisih nilai eror keduanya yang tidak berbeda jauh. Nilai RPD dari spektrum yang dikoreksi dengan OSC cukup tinggi yaitu 6.62. Hal ini menandakan ketangguhan suatu model. Nilai RPD $<1.5$ menyatakan bahwa model kalibrasi tersebut tidak dapat digunakan, $1.5<\mathrm{RPD}<2.0$ menjadikan model tersebut dapat digunakan untuk membedakan variasi dari data sedangkan nilai RPD>2 menunjukkan model predksi yang baik dan RPD > 3 adalah model yang sangat baik (Saeys et al., 2005).

\section{SIMPULAN}

Pada penelitian ini dapat disimpulkan bahwa spektroskopi UV-Vis-NIR dapat digunakan untuk menduga nilai kadar air buah cabai rawit domba dan metode koreksi spektra yang menghasilkan model kalibrasi terbaik yaitu OSC. Model kalibrasi dengan metode OSC menghasilkan nilai R kalibrasi, RMSEC, $\mathrm{R}$ validasi, RMSECV, RPD dan faktornya yaitu $0.99,0.31,0.98,0.68,6.62$ dan 4 .

\section{DAFTAR PUSTAKA}

Anoraga, S. B., Sabarisman, I., \& Ainuri, M. (2018). Effect of different pretreatments on dried chilli (Capsicum annum L.) quality. IOP Conference Series: Earth and Environmental Science, 131(1), 1-5. https://doi.org/10.1088/1755-

1315/131/1/012014

Blakey, R. J., \& Rooyen, Z. Van. (2011). Nondestructive measurement of moisture content using handheld NIR. South African Avocado Growers Association Yearbook, 34, 9-11.

Iqbal, Z., Herodian, S., \& Widodo, S. (2014). Pendugaan Kadar Air dan Total Karoten Tandan Buah Segar (TBS) Kelapa Sawit Menggunakan NIR Spektroskopi. Jurnal Keteknikan Pertanian, 2(2), 111-116.

Jantra, C., Slaughter, D. C., Liang, P. S., \& Pathaveerat, S. (2017). Nondestructive determination of dry matter and soluble solids content in dehydrator onions and garlic using a handheld visible and near infrared instrument. Postharvest Biology and Technology, 133(November), 98-103. https://doi.org/10.1016/j.postharvbio.201 7.07.007

Khairiah, Setiasih, I. S., Sukarminah, E., \& Kusumiyati. (2019). Effect of Type and Maturity on Water Content of Three Varieties of Hot Chilli (Capsicum frustencent L, Catas, Segana End Domba Variety). IOP Conference Series: Materials Science and Engineering, 506(1), 1-6. https://doi.org/10.1088/1757899X/506/1/012041

Kurniasari, I., Purwanto, Y. A., Wayan Budiaastra, I., \& Ridwani, S. (2017). Prediksi Tanin dan Total Padatan TIdak Terlarut Buah Kesemek (Diospyros kaki L.) Menggunakan Spektroskopi NIR. Jurnal Keteknikan Pertanian, 5(3), 245252. https://doi.org/DOI: 10.19028/jtep.05.3.245-252

Kusumiyati, Hadiwijaya, Y., \& Elisa Putri, I. (2018). Determination of Water Content of Intact Sapodilla Using Near Infrared Spectroscopy. IOP Conference Series: Earth and Environmental Science, 
207(2019), https://doi.org/10.1088/17551315/207/1/012047

Kusumiyati, Hadiwijaya, Y., Putri, I. E., Mubarok, S., \& Hamdani, J. S. (2020). Rapid and non-destructive prediction of total soluble solids of guava fruits at various storage periods using handheld near-infrared instrument. IOP Conference Series: Earth and Environmental Science, 458(1). https://doi.org/10.1088/17551315/458/1/012022

Mireei, S., Mohtasebi, S., Massudi, R., Rafiee, S., Arabanian, A., \& Berardinelli, A. (2010). Non-destructive measurement of moisture and soluble solids content of Mazafati date fruit by NIR spectroscopy. Australian Journal of Crop Science, 4(3), 175-179.

Munawar, A. A., von Hörsten, D., Wegener, J. K., Pawelzik, E., \& Mörlein, D. (2016). Rapid and non-destructive prediction of mango quality attributes using Fourier transform near infrared spectroscopy and chemometrics. Engineering in Agriculture, Environment and Food, 9(3), 208-215.

https://doi.org/10.1016/j.eaef.2015.12.004

Nicolaï, B. M., Beullens, K., Bobelyn, E., Peirs, A., Saeys, W., Theron, K. I., \& Lammertyn, J. (2007). Nondestructive measurement of fruit and vegetable quality by means of NIR spectroscopy: A review. Postharvest Biology and Technology, 46(2), 99-118. https://doi.org/10.1016/j.postharvbio. 200 7.06.024

Pasquini, C. (2003). Review Near Infrared Spectroscopy: Fundamentals , Practical Aspects and Analytical Applications. $J$.
Braz. Chem. Soc., 14(2), 198-219.

Ramadhan, S., Munawar, A. A., \& Nurba, D. (2016). Aplikasi NIRS dan Principal Component Analysis (PCA) untuk Mendeteksi Daerah Asal Biji Kopi Arabika (Coffea arabica). Jurnal Ilmiah Mahasiswa Pertanian, 1(1), 954-960. https://doi.org/10.17969/jimfp.v1i1.1182

Ramdani, H., Wicaksono, R. A., \& Fachruddin, M. A. (2019). Penambahan Natrium Metabisulfit $\left(\mathrm{Na}_{2} \mathrm{~S}_{2} \mathrm{O}_{5}\right)$ terhadap Vitamin $\mathrm{C}$ dan Warna pada Proses Pengeringan Cabai Merah (Capsicum annuum L.) dengan Tunnel Dehydrator. Jurnal Agronida, 4(2), 88-97. https://doi.org/10.30997/jag.v4i2.1572

Rinnan, A., Berg, F. van den, \& Engelsen, S. B. (2009). Review of the most common preprocessing techniques for near-infrared spectra. TrAC - Trends in Analytical Chemistry, 28(10), 1201-1222. https://doi.org/10.1016/j.trac.2009.07.007

Saad, A. G., Jaiswal, P., \& Jha, S. N. (2014). Non-destructive quality evaluation of intact tomato using VIS-NIR spectroscopy. International Journal of Advanced Research 2(12), 632-639.

Saeys, W., Mouazen, A. M., \& Ramon., H. (2005). Potential for onsite and online analysis of pig manure using visible and near infrared reflectance spectroscopy. Biosyst. Eng, 91(4), 393-402.

Williams, P. (2007). Application to agricultural and marine products. In: Ozaki, Y., McClure, W.F., Christy, A.A. (Eds.), NearInfrared Spectroscopy in Food Science and Technology. John Wiley \& Sons, Inc. Publication. 